University of Nebraska - Lincoln

DigitalCommons@University of Nebraska - Lincoln

Sociology Department, Faculty Publications

Sociology, Department of

2009

Discrepancies in Reporting of Physical and Sexual Abuse Among Homeless Young Adults

Kimberly A. Tyler

University of Nebraska-Lincoln, kim@ktresearch.net

Lisa A. Melander

University of Nebraska-Lincoln, Imeland@ksu.edu

Follow this and additional works at: https://digitalcommons.unl.edu/sociologyfacpub

Part of the Sociology Commons

Tyler, Kimberly A. and Melander, Lisa A., "Discrepancies in Reporting of Physical and Sexual Abuse Among Homeless Young Adults" (2009). Sociology Department, Faculty Publications. 75.

https://digitalcommons.unl.edu/sociologyfacpub/75

This Article is brought to you for free and open access by the Sociology, Department of at DigitalCommons@University of Nebraska - Lincoln. It has been accepted for inclusion in Sociology Department, Faculty Publications by an authorized administrator of DigitalCommons@University of Nebraska - Lincoln. 
This is an electronic version of an article published in Journal of Child Sexual Abuse 18 (2009), pp. 513-531; doi: 10.1080/10538710903183360 Copyright (C) Taylor \& Francis Group, LLC. Used by permission. http://www.informaworld.com/

This research was supported by a grant from the National Institute of Mental Health (K01MH064897), Dr. Kimberly A. Tyler, PI. A special thanks to Katie Johnson for her comments and suggestions on an earlier version of this paper.

Submitted October 30, 2007; revised April 17, 2008; accepted June 28, 2009.

\title{
Discrepancies in Reporting of Physical and Sexual Abuse Among Homeless Young Adults
}

\author{
Kimberly A. Tyler and Lisa A. Melander \\ University of Nebraska-Lincoln, Lincoln, Nebraska, USA \\ Corresponding author - Kimberly A. Tyler, University of Nebraska-Lincoln, \\ Department of Sociology, 717 Oldfather Hall, Lincoln, NE 68588-0324; \\ email kim@ktresearch.net
}

\begin{abstract}
This study investigated risk factors for discrepant reporting of physical and sexual abuse among 172 homeless young adults. Discrepant reporting includes situations in which a respondent denies experiencing abuse in general but reports being a victim of specific forms of maltreatment. The results revealed that discrepant reporting rates tended to be highest for minor physical assault and for noncontact sexual abuse. Multivariate results revealed that demographic characteristics were important correlates of both discrepant physical and sexual abuse reporters. Family background characteristics also played a role in discrepant reporting for physical abuse. Overall, some young people with abuse histories are not adequately labeling their maltreatment experiences and, as a result, may not be receiving the necessary treatment.
\end{abstract}

Keywords: abuse, discrepant reporting, homeless

According to the United States Department of Health and Human Services (DHHS) (2007), approximately 899,000 children were victims of child maltreatment during 2005. Of this number, almost 150,000 were physically abused and approximately 84,000 were sexually abused. In addition to these substantiated cases, numerous incidences of child abuse and neglect are never 
reported and thus do not come to the attention of authorities; other cases are unsubstantiated. As such, it is important to understand the extent to which adolescents are discrepant reporters, because failure to recognize abuse or label it as such will likely decrease the chances of appropriate intervention. Discrepant reporting refers to situations in which a respondent denies experiencing abuse in general but reports being a victim of specific forms of maltreatment during the same interview. For example, an individual who denies ever experiencing physical abuse but discloses that they had been hit with a fist by a caretaker would be considered a discrepant reporter. Additionally, it is also important to investigate whether certain characteristics such as gender or race are associated with discrepant reporting so that affected groups can be targeted for specific intervention, as many adolescents who do not recognize what constitutes abuse or are unwilling to label certain abusive experiences as such may not be receiving adequate treatment.

Although previous studies have examined discrepant reporting, these generally have been conducted with clinical samples (Dill, Chu, Grob, \& Eisen, 1991; Lipschitz, Bernstein, Winegar, \& Southwick, 1999; Ney, Moore, McPhee, \& Trought, 1986); therefore, there is a relative dearth of literature that has focused on high-risk populations. As such, we examine discrepant reporting among young homeless people, given their exceptionally high rates of physical and sexual abuse (Tyler \& Cauce, 2002; Tyler, Hoyt, Whitbeck, \& Cauce, 2001; Whitbeck \& Hoyt, 1999). Specifically, the purpose of the current study was to examine discrepant reporting of single-item indicators for both physical and sexual abuse with several items from the Conflict Tactics Scale (CTS; Straus, Hamby, Finkelhor, Moore, \& Runyan, 1998) and a sexual abuse scale tailored to homeless research among a sample of homeless young adults. Additionally, using multivariate analyses, the present study examined whether discrepant reports of sexual and physical abuse vary by demographic and family background characteristics.

\section{Literature Review}

Although past research has shown that some individuals deny or minimize abusive situations (Femina, Yeager, \& Lewis, 1990; Rausch \& Knutson, 1991; Stein \& Lewis, 1992; Varia, Abidin, \& Dass, 1996), thereby calling into question the reliability of some maltreatment reports, overall there is an absence of literature in this area, especially when examining homeless young adults. In fact, no articles focusing on homeless populations and discrepant reporting were found during an extensive literature search. Several of the studies that do examine discrepant reporters, albeit not specific to homeless populations, tend to focus on the different structures of questionnaires used to elicit child maltreatment information. For example, in their study of in- 
patient adolescents, Lipschitz and colleagues (1999) compared two different standardized childhood abuse surveys. When administered to the same patients during their second week of hospitalization, one survey elicited more frequent reports of child abuse because it was more sensitive to less severe cases of child maltreatment than the other survey format. Similarly, Berger, Knutson, Mehm, and Perkins (1988) conducted a study on adolescents with confirmed histories of child maltreatment to determine their personal perceptions of abuse. Despite the documented reports of physical abuse, relatively few respondents affirmed the statement "I was physically abused by my parents when I was a child" (Berger et al., 1998, p. 255). Consequently, the authors noted the importance of assessing discrete disciplinary events rather than asking general abuse questions.

Despite the different populations and survey environments, it is evident that there have been reliability issues with child maltreatment self-reports. Some studies on child abuse reporting accuracy focus on the victims' disclosures of abuse rather than discrepant reporting (Paine \& Hansen, 2002). Disclosure studies generally occur in two formats. In the first version, individuals who admit experiencing maltreatment are generally asked to disclose the details of their abusive experiences and are then reinterviewed at a later date about the same incidents (Stander, Olson, \& Merrill, 2002). Alternatively, the subjects of a disclosure study may also include children referred to a clinic after an alleged sexual abuse incident who are interviewed to determine if they are willing to personally disclose the abuse when asked specifically about the incident (DeVoe \& Faller, 1999; DiPietro, Runyan, \& Fredrickson, 1997; Kel$\operatorname{logg} \&$ Hoffman, 1995). The objective of both study designs is to determine reporting accuracy. Disclosure studies are different from discrepant reporting research, however, because the latter deny experiencing abuse in general (e.g., ever experienced physical abuse) but then report that they have experienced specific forms of abuse (e.g., been hit by a parent). The general denial of abuse coupled with the affirmation of specific abusive incidents characterizes the respondent as a discrepant reporter. Although some literature uses the terms disclosure and discrepant reporting interchangeably, the current study focuses on discrepant reporting as defined above.

There is a lack of research on demographics and discrepant reporting. Although the findings vary, the demographic characteristics of youth have been shown to be associated with abuse disclosure. That is, some research finds that males are less likely to disclose compared to females (Buhrmester \& Prager, 1995; DeVoe \& Faller, 1999; Hershkowitz, Horowitz, \& Lamb, 2005; Stander et al., 2002), whereas others find no gender differences (DiPietro et al., 1997; Goodman-Brown, Edelstein, Goodman, Jones, \& Gordon, 2003; Kellogg \& Hoffman, 1995; Varia et al., 1996). Although disclosure studies that focus on race and ethnicity are limited (Paine \& Hansen, 2002), some researchers have found that Whites are more likely to disclose (Lon- 
don, Bruck, Ceci, \& Shuman, 2005; Stander et al., 2002; Toukmanian \& Brouwers, 1998); other researchers find no ethnic differences (Bottoms, Rudnicki, \& Epstein, 2007; Kellogg \& Hoffman, 1995; London, Bruck, Ceci, \& Shuman, 2007). In terms of age, disclosure research is equivocal, with some studies finding that older children are more likely to disclose than younger children (Buhrmester \& Prager, 1995; DiPietro et al., 1997; Goodman-Brown et al., 2003; Hershkowitz et al., 2005). Others, however, assert that the age at the time of abuse is not consistently associated with disclosure prevalence (London et al., 2005). Similarly, one study focused on the age of the victim at the time of the retrospective interview in adulthood and found that age was not significantly associated with disclosure (Bottoms et al., 2007). Finally, the type and severity of the abuse that one experiences is associated with the level of disclosure with reporting being less likely at the extremes of the spectrum of abuse severity (Arata, 1998; Gomes-Schwartz, Horowitz, \& Cardarelli, 1990). In contrast, however, Kellogg and Hoffman (1995) found that respondents were more likely to disclose penetrating trauma compared to nonpenetrating types of sexual trauma. Overall, the findings to date are inconsistent with regard to the effect that demographic characteristics have on abuse disclosure (London et al., 2005), indicating a need for more research in this area.

\section{Hypotheses}

Because not all youth and/or young adults recognize the numerous behaviors that are generally defined as sexual and/or physical abuse and perhaps believe that some level of abuse is normative, many of these young people are likely to be discrepant reporters on certain forms of child maltreatment. As such, it was hypothesized that the young adults in our sample will be more likely to be discrepant reporters on minor forms of physical abuse compared to more severe forms and on noncontact sexual abuse items versus contact sexual abuse items (Kellogg \& Hoffman, 1995). In addition, it was hypothesized that males and non-Whites will be more likely to be discrepant reporters because males may be unwilling to discuss abuse experiences due to societal gender expectations of being strong and self-sufficient (Faller, 1989), and non-Whites may experience cultural barriers to reporting (London et al., 2005; Toukmanian \& Brouwers, 1998). It was also expected that higher levels of education would decrease the odds of discrepant reporting (Hershkowitz, Horowitz, \& Lamb, 2007) because young adults with more education may be more informed about what constitutes abuse. Additionally, it was hypothesized that experiencing a greater number of foster care placements, lower levels of caretaker warmth and/or support (Elliott \& Briere, 1994; Lawson \& Chaffin, 1992), and more caretaker neglect would decrease the odds of discrepant reporting for both physical and sexual abuse because young people 
with these familial characteristics may be less invested in protecting caretakers who exhibit detached parenting styles. Specifically, some researchers have found that those who made a prior disclosure disclosed again in a formal interview (DeVoe \& Faller, 1999; DiPietro et al., 1997). That is, prior disclosure predicts subsequent disclosure. This is particularly relevant for foster care youth who are most often in care due to reports of abuse and thus are likely to disclose again. Finally, the analyses control for age and sexual orientation. Although very little research exists within these hypothesized areas, it is especially lacking on the effects of neglect. As such, we consider our final hypothesis exploratory.

\section{Method}

Data are from the Homeless Young Adult Project, a pilot study designed to examine the effect of neglect and abuse histories on homeless young adults' mental health and high-risk behaviors. Over a period of approximately one year (from April 2004 through June 2005), 199 young adults were interviewed in three Midwestern cities including Des Moines, Iowa, and Omaha and Lincoln, Nebraska. Of this total, 144 were homeless and 55 were housed at the time of the interview. Despite being housed at the time of the interview, 28 out of the 55 housed young adults had extensive histories of being homeless and had run away from home numerous times. In fact, the 28 housed young adults with run away histories reported running away more times than the homeless individuals $(M=5.72$ vs. 4.99$)$, but this difference was not statistically significant. What differentiated these two groups was their housing status at the time of the interview, indicating that homelessness is a situation that is very fluid and not easily defined (Wright, 1991). The final sample included 172 young adults who were homeless at the time of the interview or had a history of running away and being homeless and who had valid data on the variables of interest.

Experienced interviewers who worked on past projects dealing with at-risk youth, served for several years in agencies and shelters that support homeless young people, and were very familiar with local street cultures (e.g., knowing where youth congregate) conducted interviews. Additionally, all interviewers had completed the Institutional Review Board (IRB) Training Initiative course for the protection of human subjects in research.

Interviewers approached shelter residents and located eligible respondents in areas where street youth and young adults congregate. Young people were interviewed using a systematic sampling strategy that maximized locating homeless young adults. This approach was used because it is well established that it is not possible to randomly sample homeless populations (Wright, Allen, \& Devine, 1995). Study eligibility required young people to be between the ages of 19 and 26 and homeless. Interviewers obtained informed 
consent from respondents prior to participation and told them about the confidentiality of the study and that their participation was voluntary. The interviews, which were conducted in shelter interview rooms or quiet corners of fast food restaurants or coffee shops, lasted approximately one hour, and all participants received a modest reimbursement for their involvement. Referrals for shelter, counseling services, and food services were offered to the young adults at the time of the interview. Although field reporters did not formally tally screening rates, they reported that very few young people refused to participate. The IRB at the author's institution approved this study.

\section{Participants}

The sample included 69 females (40.1\%) and 103 males (59.9\%). Of these, 31 respondents $(18.5 \%)$ self-identified as gay, lesbian, or bisexual (GLB). The actual age of the sample ranged from 19 to 26 years with a mean of 21.45 years. The majority of the sample was White $(80 \%)$ but $9 \%$ were Black or African American, 4\% Hispanic or Latino, 2\% American Indian or Alaskan Native, $1 \%$ Asian, and $5 \%$ biracial or multiracial. Thirteen percent of respondents had a 9th grade education or less, $9 \%$ completed 10 th grade, $15 \%$ completed 11 th grade, and almost 37\% completed high school. Finally, 16\% obtained their GED and $11 \%$ of young adults had completed some college. Thirty-six percent of all respondents spent some time in foster care: $14 \%$ had been in foster care once, $15 \% 2$ to 5 times, and $7 \%$ had been in foster care 6 or more times.

\section{Measures}

\section{Demographic Characteristics}

Age was a continuous variable that measured how old the young adults were at the time of the interview. Gender was coded $0=$ male and $1=$ female. Race was coded $0=$ non-White and $1=$ White. Sexual orientation was assessed by asking respondents how they would describe their sexual orientation. Those who said they were straight or heterosexual were coded as 1 and those who said they were GLB were coded as 0. Education was a continuous variable that ranged from $0=$ completed the seventh grade or less to $7=$ completed some college.

\section{Family Background Characteristics}

Foster care was an open-ended question that asked respondents how many times they had ever lived in foster care. Responses ranged from 0 to 50 times. In order to account for skew, responses were collapsed and the resulting scale 
ranged from 0 (never) to 4 (11 to 50). For the following items, a caretaker was defined as the individual who helped raise the respondent and the person that took care of him or her and whom he or she spent the most time with. For the majority of respondents $(79 \%)$, this person was a mother or father.

Warmth included 13 items from the Parental Social Support for Adolescents Scale (Aneshensel \& Sucoff, 1996), which asked respondents, for example, whether their caretaker "understood them," "trusted them," "cared about their feelings," and "made them feel wanted." Response categories ranged from 0 (strongly disagree) to 3 (strongly agree). Certain items were reverse coded so higher scores indicated greater warmth. A mean scale was created and the alpha reliability was .96 .

Neglect was comprised of five items from a supplementary scale within the Parent-Child Conflict Tactics Scale (Straus et al., 1998). These items asked respondents how many times their caretaker left them home alone when someone should have been with them, was not able to show or tell them that they were loved, was not able to give them the food they needed, did not take them to the doctor/hospital when they needed to go, and was drunk or high on drugs and could not take care of them. Individual items were first dichotomized and then summed so that a higher score indicated more types of neglect. We did not include a comparison of discrepant reporting for neglect because our focus is on physical and sexual abuse only. The alpha reliability for neglect was .78 .

Physical abuse was measured using 12 individual items from the CTS (Straus et al., 1998). Respondents were asked to reflect on abusive experiences that occurred prior to age 18 and asked how frequently their caretaker, for example, shook them; hit them on the bottom with something like a belt, stick, or other hard object; or hit them with a fist or kicked them hard. These individual items were dichotomized ( $0=$ never, $1=$ at least once) for the purposes of the analyses. Overall, 79\% of young adults indicated a positive response to at least 1 of the 12 items from the CTS.

Sexual abuse was measured using five items adapted from previous research with homeless youth (Whitbeck \& Simons, 1990). Respondents were asked to indicate before they were on their own (when they were under 18) how often any adult or someone at least five years older asked them to do something sexual; watched them do something sexual (e.g., masturbate); touched them sexually; had them touch him or her sexually, such as on his or her butt, thigh, breast, or genitals ("private parts"); and put or tried to put anything or any part of his or her body into them sexually (like into their vagina, butt, or mouth). Responses ranged from 0 (never) to 7 (more than once a day). For the purpose of the analyses, these items were dichotomized $(0=$ never, 1 = at least once). Overall, $46 \%$ of young people indicated a positive response to at least one item from this scale. 


\section{Discrepant Reporting}

Discrepant reporting of physical and sexual abuse was measured and analyzed in two ways. Respondents were asked (1) "Were you ever physically abused as a child (under age 18)?" and (2) "Were you ever sexually abused as a child (under 18)?" Each of these two items were dichotomous ( $0=$ no, $1=$ yes). Fifty-four percent of respondents reported being physically abused and 33\% said they were sexually abused according to these single item indicators. The young adults' answers to the single item "Were you ever physically abused as a child (under age 18)?" were compared to their answers to each of the individual physical abuse items (e.g., "Did your caretaker ever hit you with a fist or kick you hard?") See Table 1. Next, respondents' answers to the single item "Were you ever sexually abused as a child (under age 18)?" were compared to their answers to each of the individual sexual abuse items (e.g., "Has anyone had you touch them sexually?") See Table 2. For the multivariate analyses, two composite variables were created by comparing the single physical and sexual abuse items (i.e., "Were you ever physically abused as a child [under age 18]?" and "Were you ever sexually abused as a child [under

Table 1. Discrepant Reporting for Physical Abuse

\begin{tabular}{|c|c|c|c|}
\hline Individual physical abuse items & $\begin{array}{l}\text { wered "Yes" } \\
\text { e individual } \\
\text { physical } \\
\text { buse item }\end{array}$ & $\begin{array}{l}\text { Answered "No" } \\
\text { when asked if they } \\
\text { had ever been } \\
\text { physically abused }\end{array}$ & $\begin{array}{l}\text { Discrepant } \\
\text { report* }^{*}\end{array}$ \\
\hline \multicolumn{4}{|l|}{ Minor physical abuse } \\
\hline Ever shook you & 45 & 14 & $31 \%$ \\
\hline $\begin{array}{l}\text { Ever hit you on the bottom with } \\
\text { belt, stick, or other hard object }\end{array}$ & 109 & 45 & $41 \%$ \\
\hline Ever pinched you & 38 & 18 & $47 \%$ \\
\hline \multicolumn{4}{|l|}{ Severe physical abuse } \\
\hline $\begin{array}{l}\text { Ever hit you with a fist or } \\
\text { kicked you hard }\end{array}$ & 45 & 14 & $31 \%$ \\
\hline $\begin{array}{l}\text { Ever hit you on some other part } \\
\text { of the body with belt, stick, or } \\
\text { other hard object }\end{array}$ & 54 & 14 & $26 \%$ \\
\hline Ever threw or knocked you down & 54 & 16 & $30 \%$ \\
\hline Ever slapped face, head, or ears & 90 & 37 & $41 \%$ \\
\hline \multicolumn{4}{|l|}{ Very severe physical abuse } \\
\hline $\begin{array}{l}\text { Ever grabbed you around the neck } \\
\text { and choked you }\end{array}$ & 24 & 6 & $25 \%$ \\
\hline $\begin{array}{l}\text { Ever beat you up by hitting you } \\
\text { over and over }\end{array}$ & 33 & 6 & $18 \%$ \\
\hline
\end{tabular}

Three items were deleted from this scale due to small cell sizes.

*Percentage in the discrepant report column was calculated by dividing the number of respondents who answered "No" when asked if they had ever been physically abused by the number of respondents who answered "Yes" to the individual physical abuse items. 
Table 2. Discrepant Reporting for Sexual Abuse

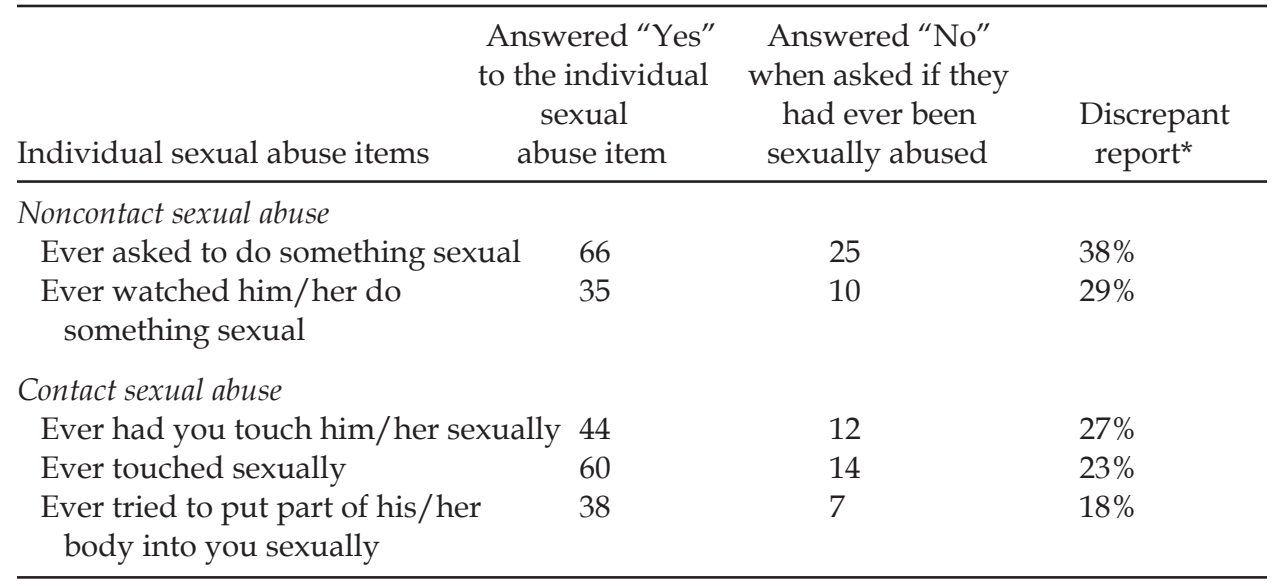

*Percentage in the discrepant report column was calculated by dividing the number of respondents who answered "No" when asked if they had ever been sexually abused by the number of respondents who answered "Yes" to the individual sexual abuse items.

age 18]?") to the overall physical and sexual abuse variables (i.e., "Have you ever experienced any of the 12 types of physical abuse and have you ever experienced any of the 5 types of sexual abuse?"). Those who were scored as 0 on the single item physical abuse question but were scored as 1 on the overall or individual physical abuse measure were coded as 1 (yes) on the discrepant reporting of physical abuse variable. All other respondents were coded as 0 (no) on the discrepant reporting of physical abuse. The same process was used for the creation of the discrepant reporting of the sexual abuse variable.

\section{Results}

Table 1 displays the results for discrepant reports on each individual physical abuse item. The percent of reports that were discrepant was calculated by dividing the number of respondents who answered "no" when asked if they had ever been physically abused by the number of respondents who answered "yes" to the individual physical abuse items. Surprisingly, several respondents were discrepant reporters on various forms of minor, severe, and very severe assault. For example, of the 45 individuals who stated that their caretaker shook them, 14 of them denied ever experiencing physical abuse. As a result, $31 \%$ of the respondents were discrepant reporters on this minor abuse item. The discrepancy report rate for the next two minor physical abuse items was $41 \%$ and $47 \%$, respectively.

In terms of severe physical abuse, although 45 respondents stated that a caretaker hit them with a fist or kicked them hard, 14 denied ever experiencing physical abuse, resulting in a 31\% discrepant reporting on this item. The 
discrepant reporting for the next three severe physical abuse items were $26 \%$, $30 \%$, and $41 \%$, respectively. In terms of very severe physical abuse, when asked about being grabbed around the neck and choked by a caretaker, six respondents confirmed that they had been very severely abused in this manner although they denied experiencing physical abuse in general. This resulted in $25 \%$ of respondents being discrepant reporters on this item. Finally, six respondents indicated that their caretakers beat them up by hitting them over and over but denied experiencing physical abuse, meaning that $18 \%$ of the respondents were discrepant reporters on this item. The pooled mean of discrepant reporting for physical abuse listed in Table 1 was $32.22 \%$ (range = $18 \%-47 \%$ ).

The discrepant reporting results for the individual sexual abuse items are shown in Table 2. The discrepant report was calculated by dividing the number of respondents who answered "no" when asked if they had ever been sexually abused by the number of respondents who answered "yes" to the individual sexual abuse items. Although 66 respondents indicated that an adult asked them to do something sexual before they were living on their own, 25 of them denied experiencing sexual abuse in general. Thus, 38\% of respondents were discrepant reporters on this item. Ten young people reported having to watch an adult do something sexual to them but denied sexual abuse in general, which indicates a discrepancy of $29 \%$ on this item. In addition, $27 \%$ (12 respondents) were discrepant reporters when asked if they had to touch an adult sexually prior to leaving home. Finally, 14 individuals denied sexual abuse even though they had been touched sexually (discrepant report of $23 \%$ ), and 7 young people denied sexual abuse despite reporting that an adult had tried to put something into them sexually, a discrepant report of $18 \%$. The pooled mean of discrepant reporting for sexual abuse listed in Table 2 was $27.0 \%$ (range $=18 \%-38 \%$ ).

Although discrepant reports tend to be higher overall for noncontact sexual abuse and minor physical abuse, we cannot say this difference is statistically significant based on the results in Tables 1 and 2. Correlational analyses, however, also confirm our hypothesis. That is, there was a stronger correlation between discrepant reporting and noncontact sexual abuse compared to contact sexual abuse. Additionally, minor forms of physical abuse were significantly associated with discrepant reporting, whereas more severe forms of physical abuse were not. Finally, results from logistic regression also confirm our hypothesis that young people were more likely to be discrepant reporters on minor forms of physical abuse and noncontact sexual abuse (results not shown).

\section{Multivariate Results}

Logistic regression was used in subsequent analyses due to the dichotomous nature of the two outcome variables (i.e., discrepant physical abuse re- 
porters versus nondiscrepant and discrepant sexual abuse reporters versus nondiscrepant). The logistic regression results for discrepant physical abuse reporters are presented in Table 3. The variables were entered in two separate blocks to examine the individual effects of each group of variables. The odds ratio, 95\% confidence interval $(\mathrm{CI})$, and $p$ values are reported. In Model 1, gender was statistically significant; that is, being female reduced the odds of being a physical abuse discrepant reporter by $69 \%(\mathrm{OR}=.31 ; 95 \% \mathrm{CI}=.14-.67)$.

Family background characteristics (i.e., history of foster care, caretaker warmth, and neglect) were entered in Model 2. For every one unit increase in number of foster care placements, there was a $46 \%$ decrease in the odds of producing a discrepant report regarding physical abuse (OR $=.54 ; 95 \% \mathrm{CI}$ $=.33-.87)$. In addition, for each additional type of neglect experienced, there was a $48 \%$ decrease in the likelihood of discrepant reporting for physical abuse $(\mathrm{OR}=.52 ; 95 \% \mathrm{CI}=.37-.74)$. Being White reduced the odds of being a physical abuse discrepant reporter by $70 \%(\mathrm{OR}=.30$; $95 \% \mathrm{CI}=.11-.80)$. Gender remained statistically significant. Overall, Model 2 represented a significant improvement in model fit with the addition of the family background variables.

The logistic regression results for discrepant sexual abuse reporters are presented in Table 4 . The variables were again entered in two separate blocks to examine the individual effects of each group of variables. The odds ratio, $95 \%$ confidence interval $(\mathrm{CI})$, and $p$ values are reported. Among the demographic variables entered in Model 1, race and education were statistically significant. That is, being White reduced the odds of being a discrepant re-

Table 3. Logistic Regression Models for Discrepant Reporting of Physical Abuse

\begin{tabular}{|c|c|c|c|c|c|c|}
\hline & \multicolumn{3}{|c|}{ Model 1} & \multicolumn{3}{|c|}{ Model 2} \\
\hline & Odds ratio & $95 \% \mathrm{CI}$ & $p$ value & Odds ratio & $95 \% \mathrm{CI}$ & $p$ value \\
\hline \multicolumn{7}{|l|}{ Demographics } \\
\hline Age & .91 & $.77-1.08$ & .273 & .86 & $.72-1.04$ & .128 \\
\hline Female & .31 & $.14-.67$ & .003 & .34 & $.14-.80$ & .014 \\
\hline White & .46 & $.20-1.08$ & .076 & .30 & $.11-.80$ & .016 \\
\hline Heterosexual & 2.29 & $.78-6.71$ & .131 & 2.64 & $.77-9.08$ & .124 \\
\hline Education & .88 & $.72-1.07$ & .204 & .83 & $.67-1.03$ & .083 \\
\hline \multicolumn{7}{|l|}{ Family background } \\
\hline Foster care & & & & .54 & $.33-.87$ & .012 \\
\hline Warmth & & & & .53 & $.27-1.07$ & .075 \\
\hline Neglect & & & & .52 & $.37-.74$ & .000 \\
\hline -2 Log likelihood & 188.281 & & & 159.587 & & \\
\hline d.f. & 5 & & & 8 & & \\
\hline Change in $\chi^{2}$ & & & & $28.694(3)^{*}$ & & \\
\hline Nagelkerke $\mathrm{R}^{2}$ & .16 & & & .36 & & \\
\hline
\end{tabular}

$N=159 ;{ }^{*} p \leq .01$ 
Table 4. Logistic Regression Models for Discrepant Reporting of Sexual Abuse

\begin{tabular}{|c|c|c|c|c|c|c|}
\hline & \multicolumn{3}{|c|}{ Model 1} & \multicolumn{3}{|c|}{ Model 2} \\
\hline & Odds ratio & $95 \% \mathrm{CI}$ & $p$ value & Odds ratio & $95 \% \mathrm{CI}$ & $p$ value \\
\hline \multicolumn{7}{|l|}{ Demographics } \\
\hline Age & 1.07 & $.87-1.31$ & .551 & 1.06 & $.86-1.32$ & .581 \\
\hline Female & .66 & $.25-1.77$ & .408 & .71 & $.26-1.95$ & .506 \\
\hline White & .37 & $.14-1.01$ & .051 & .25 & $.08-.73$ & .012 \\
\hline Heterosexual & 1.49 & $.39-5.70$ & .562 & 1.62 & $.41-6.48$ & .494 \\
\hline Education & .66 & $.52-.84$ & .001 & .65 & $.50-.84$ & .001 \\
\hline \multicolumn{7}{|l|}{ Family background } \\
\hline Foster care & & & & .74 & $.41-1.32$ & .309 \\
\hline Warmth & & & & .45 & $.20-1.02$ & .055 \\
\hline Neglect & & & & .84 & $.59-1.19$ & .319 \\
\hline -2 Log likelihood & 126.502 & & & 120.203 & & \\
\hline d.f. & 5 & & & 8 & & \\
\hline Change in $x^{2}$ & & & & $6.299(3)$ & & \\
\hline Nagelkerke $\mathrm{R}^{2}$ & .17 & & & .23 & & \\
\hline
\end{tabular}

$N=156$.

porter by $63 \%(\mathrm{OR}=.37 ; 95 \% \mathrm{CI}=.14-1.01)$ and a one unit increase in education decreased the odds of being a discrepant reporter by $34 \%(\mathrm{OR}=.66 ; 95 \%$ $\mathrm{CI}=.52-.84)$.

Family background characteristics (i.e., history of foster care, caretaker warmth, and neglect) were included in Model 2, but none of these variables were significant at the .05 level. Race and education remained significant. Overall, Model 2 did not represent a significant improvement in model fit with the addition of the family background variables.

\section{Discussion}

The purpose of this study was to investigate discrepant reporting of physical and sexual abuse among homeless young adults and to use multivariate analyses to examine demographic and family background characteristics as risk factors for discrepant reporting. Very few studies have examined discrepant reporting among youth and young adults in general and homeless individuals in particular. Discrepant reporting has significant implications among this population, however, given that homeless individuals experience exceptionally high rates of abuse. Failure to classify the experiences as abusive may result in inadequate treatment, which may have long-term effects. Additionally, these findings have important implications for how abuse is measured and how young people are questioned about abuse in survey research.

The results for the current study reveal high rates of discrepant reporting of both physical and sexual abuse among homeless young adults. As hypothesized, the rates for discrepant physical abuse are significantly higher for mi- 
nor forms of physical abuse. Even for the more severe forms of physical abuse (e.g., thrown or knocked down), however, almost one-third of our sample did not label these incidents as maltreatment. This suggests that some homeless individuals may not view these behaviors as a form of physical abuse but perhaps view them as normative or may be unwilling to admit experiencing abuse due to embarrassment or social desirability. Similarly, young people are significantly more likely to be discrepant reporters on noncontact sexual abuse items compared to contact sexual abuse items, suggesting that some homeless young people may not recognize this type of behavior as abuse and therefore do not label it as such. The lowest rate of discrepant sexual abuse reported in the current study was for the penetration item, which is consistent with previous research (Kellogg \& Hoffman, 1995). It is possible that young adults are more likely to recognize penetration as sexual abuse and therefore are less likely to be a discrepant reporter on this type of maltreatment. In contrast, some researchers have found that disclosure tends to be less likely at the extremes of the spectrum of abuse severity (Arata, 1998; Gomes-Schwartz et al., 1990).

In terms of the multivariate findings for physical abuse discrepant reporting, results reveal that demographic characteristics matter. That is, being male and non-White increased the odds of discrepant reporting of physical abuse, which is consistent with some of the literature and the current hypotheses. That is, males are more likely to initially deny experiencing abuse in general (DeVoe \& Faller, 1999; Rew \& Esparza, 1990; Stander et al., 2002), whereas Whites are more likely to report abuse (London et al., 2005; Stander et al., 2002). Some young men may be unwilling to label physically abusive experiences as such because admitting to themselves and to others that they have been abused may undermine their sense of masculinity, given the societal gender expectations that males are expected to be strong and self-sufficient (Faller, 1989). Additionally, a certain degree of violence and toughness is generally associated with "maleness" in our culture. As such, it may be easier for them to view physical abuse as more normative and perhaps more acceptable behavior. Furthermore, because minority youth are more likely to face complex sets of barriers to receiving services (Kazarian \& Kazarian, 1998) and receive fewer services compared to Whites (Scheppers, van Dongen, Dekker, Geertzen, \& Dekker, 2006), they may be more likely to be discrepant reporters because they may view the resources available to them as limited. Additionally, minority youth also experience language barriers, social isolation, discrimination, and deportation concerns (Kazarian \& Kazarian, 1998), which may also account for the discrepancy in reporting. Also, differences in cultures may play a role in determining an individual's willingness to disclose (Futa, Hsu, \& Hansen, 2001; Toukmanian \& Brouwers, 1998). Finally, although we controlled for sexual orientation because sexual minority individuals have been found to experience higher rates of maltreatment, the current study finds no difference between heterosexual and sexual minority respon- 
dents in terms of their discrepant reporting. Because very few studies to date have examined this link, this is an important area for future research.

Two of the family background characteristics were significantly associated with physical abuse discrepant reporting. Consistent with what was hypothesized, experiencing a greater number of foster care placements and more types of neglect decreased the odds of physical abuse discrepant reporting. It is possible that young adults who have experienced more placements believe they have nothing to lose by reporting abuse, whereas those living with a biological parent may have a sense of loyalty and thus be less willing to report abuse. This finding is consistent with DiPietro and colleagues (1997) and DeVoe and Faller (1999) who found that prior disclosure predicts subsequent disclosure. This is particularly relevant for foster care youth who are most often in care due to abuse being reported and thus are likely to disclose again. Similarly, neglected youth may feel little responsibility toward protecting their neglectful parent and, consequently, may be more likely not only to report specific abusive experiences but also to admit experiencing abuse in general.

The findings for sexual abuse discrepant reporting indicate that two demographic variables were significant: being non-White and having lower levels of education increased the odds of being a discrepant reporter, which is consistent with what was hypothesized and with the literature. Again, it is possible that non-Whites are likely to be discrepant reporters due to cultural differences in disclosure willingness (Futa et al., 2001; Toukmanian \& Brouwers, 1998) and perceived barriers to services (Kazarian \& Kazarian, 1998). Additionally, those with lower educational attainment may not be as informed as to what constitutes abuse and therefore may be more likely to fail to classify the experiences as abusive. Our finding on education is consistent with the literature, which finds that more education is linked to disclosure (Hershkowitz et al., 2007). It is interesting to note that no gender effect was found, which is contrary to what was expected but consistent with other studies (DiPietro et al., 1997; Goodman-Brown et al., 2003; Kellogg \& Hoffman, 1995; Varia et al., 1996). One possible explanation for the absence of a gender difference is that what constitutes sexual abuse is more clearly defined compared to what comprises physical abuse and, as such, both males and females may be equally likely to label sexually abusive experiences as maltreatment. This assertion is supported by Hershkowitz and colleagues (2005), who found that children are less likely to make allegations for physical abuse compared to sexual abuse.

None of the family background variables reached significance for sexual abuse discrepant reporters. The absence of findings may be attributed to the lower percentages of discrepant reporting on the individual sexual abuse items compared to the physical abuse items. In addition, it is also possible that the sexual abuse items do not fully capture the sexually abusive experiences of homeless youth. That is, these young people may experi- 
ence a wider range of sexual abuse that was not captured by the five indicators used in this study. In fact, we found that there were seven respondents who said "yes" to the general sexual abuse question but "no" to the specific item indicators (results not shown), indicating that we are still missing some forms of abuse even when utilizing scales frequently used with this population. This underscores the importance of using multiple indicators when inquiring about abuse experiences. Overall, the findings indicate that some young adults are failing to classify certain experiences as sexual abuse, which may be due to inadequate education, embarrassment, social desirability, feelings of responsibility for the abuse, or the items not encompassing the types of sexual abuse that some of these young people have experienced.

Some limitations should be noted. First, all data are based on self-reports. Despite this, participants were informed that their responses would be confidential, and the interviewers were already known and trusted by many of the young people so it is less likely that the respondents would be motivated to bias their responses. Moreover, past comparisons of the responses of runaway adolescents to those of their parents reveal that these young people do not appear to be overreporting abuse within the home (Whitbeck, Hoyt, \& Ackley, 1997). Another limitation is the retrospective nature of many of the measures, which may have resulted in some over- or underreporting (e.g., being asked to identify abuse that occurred while they were a child). Next, this study was cross-sectional; therefore, inferences cannot be made about causality. Finally, although the CTS provides measures to assess a variety of forms of physical abuse, the context and severity of the violent incidents remains unknown.

Despite these limitations, this paper also has numerous strengths. First, the study included large enough numbers of both males and females, which allowed for gender comparisons. Second, the study included multiple indicators of both sexual and physical abuse, allowing for the examination of discrepant reporting, an area that is lacking in the literature on homeless young adults. Additionally, most studies focus only on sexual abuse disclosure thus failing to account for other types of child maltreatment (Bottoms et al., 2007). Finally, in addition to examining discrepant reporting, the current study also examined demographic and family risk factors associated with discrepant reporting.

\section{Practice Implications}

Delivering treatment to homeless young adults tends to pose challenges to service providers, especially when these individuals are likely to underreport or minimize their abuse experiences. Certain groups of homeless young adults, including males and minorities, may underreport abuse due to soci- 
etal expectations and/or cultural barriers, potentially posing difficulties for service providers. These findings have important implications for intervention strategies because abuse can have long-term social, economic, and personal consequences, and many young adults may not be receiving appropriate treatment. Homeless young people do not trust most adults because of previous negative interactions; therefore, service providers need to be aware that these clients may be unwilling to discuss their abuse experiences. They also should be aware that without intervention, many of these young people are at risk for continued exploitation. Thus, one important goal of any intervention is to help homeless young people learn to differentiate between adults and peers worthy of trust so that these young people can discuss their abusive experiences and receive treatment to circumvent future victimization.

In addition to having practical implications for service providers, these findings also provide new frontiers for future research. Because the results indicate that males and minorities are more likely to be discrepant reporters, future research should examine whether these individuals are discrepant reporters due to societal expectations and/or cultural barriers or whether it is due to other reasons such as not understanding what constitutes different forms of abuse. If it is the latter, then it will be important to educate youth and young adults about what behaviors are considered abuse and convey to them the importance of reporting it. Additionally, acknowledging that numerous homeless young adults experience maltreatment but do not label it as such signals to service providers and researchers that these young people need to be asked about abuse in numerous ways. For example, relying on multiple indicator instruments as opposed to single item measures is likely to provide a more accurate account of the actual level of abuse that homeless young adults have experienced. Not only will this practice lead to more accurate estimates of the prevalence of child maltreatment, but it may also allow for early intervention with specific groups who are at greater risk of failing to acknowledge that these events constitute abuse.

\section{References}

Aneshensel, C. S., \& Sucoff, C. A. (1996). The neighborhood context of adolescent mental health. Journal of Health and Social Behavior, 37, 293-310.

Arata, C. M. (1998). To tell or not to tell: Current functioning of child sexual abuse survivors who disclosed their victimization. Child Maltreatment, 3, 63-71.

Berger, A. M., Knutson, J. F., Mehm, J. G., \& Perkins, K. A. (1988). The self-report of punitive childhood experiences of young adults and adolescents. Child Abuse \& Neglect, 12, 251-262.

Bottoms, B. L., Rudnicki, A. G., \& Epstein, M. A. (2007). A retrospective study of factors affecting the disclosure of childhood sexual and physical abuse. In M. E. Pipe, M. E. Lamb, Y. Orbach, \& A. C. Cederborg (Eds.), Child sexual abuse: 
Disclosure, delay, and denial (pp. 175-194). Mahwah, NJ: Lawrence Erlbaum Associates.

Buhrmester, D., \& Prager, K. (1995). Patterns and functions of self-disclosure during childhood and adolescence. In K. J. Rotenberg (Ed.), Disclosure processes in children and adolescence (pp. 10-56). New York: Cambridge University Press.

DeVoe, E. R., \& Faller, K. C. (1999). The characteristics of disclosure among children who may have been sexually abused. Child Maltreatment, 4, 217-227.

Dill, D. L., Chu, J. A., Grob, M. C., \& Eisen, S. V. (1991). The reliability of abuse history reports: A comparison of two inquiry formats. Comprehensive Psychiatry, 32, 166-169.

DiPietro, E. K., Runyan, D. K., \& Fredrickson, D. D. (1997). Predictors of disclosure during medical evaluation for suspected sexual abuse. Journal of Child Sexual Abuse, 6, 133-142.

Elliott, D. M., \& Briere, J. (1994). Forensic sexual abuse evaluations of older children: Disclosures and symptomatology. Behavioral Sciences $\mathcal{E}$ the Law, 12, 261-277.

Faller, K. C. (1989). Characteristics of a clinical sample of sexually abused children: How boy and girl victims differ. Child Abuse E Neglect, 13, 281-291.

Femina, D. D., Yeager, C. A., \& Lewis, D. O. (1990). Child abuse: Adolescent records vs. adult recall. Child Abuse \& Neglect, 14, 227-231.

Futa, K. T., Hsu, E., \& Hansen, D. J. (2001). Child sexual abuse in Asian American families: An examination of cultural factors that influence prevalence, identification, and treatment. Clinical Psychology: Science \& Practice, 8, 189-209.

Gomes-Schwartz, B., Horowitz, J. M., \& Cardarelli, A. P. (1990). Child sexual abuse: The initial effects. Newbury Park, CA: Sage Publications.

Goodman-Brown, T. B., Edelstein, R. S., Goodman, G. S., Jones, D. P., \& Gordon, D. S. (2003). Why children tell: A model of children's disclosure of sexual abuse. Child Abuse \& Neglect, 27, 525-540.

Hershkowitz, I., Horowitz, D., \& Lamb, M. E. (2005). Trends in children's disclosure of abuse in Israel: A national study. Child Abuse \& Neglect, 29, 1203-1214.

Hershkowitz, I., Horowitz, D., \& Lamb, M. E. (2007). Individual and family variables associated with disclosure and nondisclosure of child abuse in Israel. In M. E. Pipe, M. E. Lamb, Y. Orbach, \& A. C. Cederborg (Eds.), Child sexual abuse: Disclosure, delay, and denial (pp. 65-75). Mahwah, NJ: Lawrence Erlbaum Associates.

Kazarian, S. S., \& Kazarian, L. Z. (1998). Cultural aspects of family violence. In S. S. Kazarian \& D. R. Evans (Eds.), Cultural clinical psychology: Theory, research, and practice (pp. 316-347). New York: Oxford University Press.

Kellogg, N. D., \& Hoffman, T. J. (1995). Unwanted and illegal sexual experiences in childhood and adolescence. Child Abuse \& Neglect, 19, 1457-1468.

Lawson, L., \& Chaffin, M. (1992). False negatives in sexual abuse disclosure interviews: Incidence and influence of caretaker's belief in abuse in cases of ac- 
cidental abuse discovery by diagnosis of STD. Journal of Interpersonal Violence, 7, 532-542.

Lipschitz, D. S., Bernstein, D. P., Winegar, R. K., \& Southwick, S. M. (1999). Hospitalized adolescents' reports of sexual and physical abuse: A comparison of two self-report measures. Journal of Traumatic Stress, 12, 641-654.

London, K., Bruck, M., Ceci, S. J., \& Shuman, D. W. (2005). Disclosure of child sexual abuse: What does the research tell us about the ways that children tell? Psychology, Public Policy, \& Law, 11, 194-226.

London, K., Bruck, M., Ceci, S. J., \& Shuman, D. W. (2007). Disclosure of child sexual abuse: A review of the contemporary empirical literature. In M. E. Pipe, M. E.

Lamb, Y. Orbach, \& A. C. Cederborg (Eds.), Child sexual abuse: Disclosure, delay, and denial (pp. 11-39). Mahwah, NJ: Lawrence Erlbaum Associates.

Ney, P. G., Moore, C., McPhee, J., \& Trought, P. (1986). Child abuse: A study of the child's perspective. Child Abuse \& Neglect, 10, 511-518.

Paine, M. L., \& Hansen, D. J. (2002). Factors influencing children to self-disclose sexual abuse. Clinical Psychology Review, 22, 271-295.

Rausch, K., \& Knutson, J. F. (1991). The self-report of personal punitive childhood experiences and those of siblings. Child Abuse \& Neglect, 15, 29-36.

Rew, L., \& Esparza, D. (1990). Barriers to disclosure among sexually abused male children: Implications for nursing practice. Journal of Child $\mathcal{E}$ Adolescent Psychiatric Nursing, 3, 120-127.

Scheppers, E., van Dongen, E., Dekker, J., Geertzen, J., \& Dekker, J. (2006). Potential barriers to the use of health services among ethnic minorities: A review. Family Practice, 23, 325-348.

Stander, V. A., Olson, C. B., \& Merrill, L. L. (2002). Self-definition as a survivor of childhood sexual abuse among navy recruits. Journal of Consulting $\mathcal{E}$ Clinical Psychology, 70, 369-377.

Stein, A., \& Lewis, D. O. (1992). Discovering physical abuse: Insights from a follow-up study of delinquents. Child Abuse E Neglect, 16, 523-531.

Straus, M. A., Hamby, S. L., Finkelhor, D., Moore, D. W., \& Runyan, D. (1998). Identification of child maltreatment with the Parent-Child Conflict Tactics Scales: Development and psycho-metric data for a national sample of American parents. Child Abuse \& Neglect, 22, 249-270.

Toukmanian, S. G., \& Brouwers, M. C. (1998). Cultural aspects of self-disclosure and psychotherapy. In S. S. Kazarian \& D. R. Evans (Eds.), Cultural clinical psychology: Theory, research, and practice (pp. 106-124). New York: Oxford University Press.

Tyler, K. A., \& Cauce, A. M. (2002). Perpetrators of early physical and sexual abuse among homeless and runaway adolescents. Child Abuse E Neglect, 26, 1261-1274. 
Tyler, K. A., Hoyt, D. R., Whitbeck, L. B., \& Cauce, A. M. (2001). The impact of childhood sexual abuse on later sexual victimization among runaway youth. Journal of Research on Adolescence, 11, 151-176.

U. S. Department of Health and Human Services, Administration on Children, Youth and Families. (2007). Child maltreatment 2005. Washington, DC: U.S. Government Printing Office.

Varia, R., Abidin, R., \& Dass, P. (1996). Perceptions of abuse: Effects on adult psychological and social adjustment. Child Abuse \& Neglect, 20, 511-526.

Whitbeck, L. B., \& Hoyt, D. R. (1999). Nowhere to grow: Homeless and runaway adolescents and their families. New York: Aldine de Gruyter.

Whitbeck, L. B., Hoyt, D. R., \& Ackley, K. A. (1997). Abusive family backgrounds and later victimization among runaway and homeless adolescents. Journal of Research on Adolescence, 7, 375-392.

Whitbeck, L. B., \& Simons, R. L. (1990). Life on the streets: The victimization of runaway and homeless adolescents. Youth \& Society, 22, 108-125.

Wright, J. D. (1991). Health and the homeless teenager: Evidence from the national health care for the homeless program. Journal of Health and Social Policy, 2, 15-36.

Wright, J. D., Allen, T. L., \& Devine, J. A. (1995). Tracking non-traditional populations in longitudinal studies. Evaluation and Program Planning, 18, 267-277.

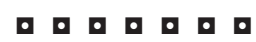

Kimberly A. Tyler, PhD, is an associate professor in the Department of Sociology at the University of Nebraska-Lincoln. Her research interests include homelessness, child abuse and neglect, victimization, and high-risk behaviors among adolescents and youth.

Lisa A. Melander, MA, is a doctoral student in the Department of Sociology at the University of Nebraska-Lincoln. Her primary research interests include intimate partner violence, child abuse and neglect, and adolescent high-risk behaviors. 